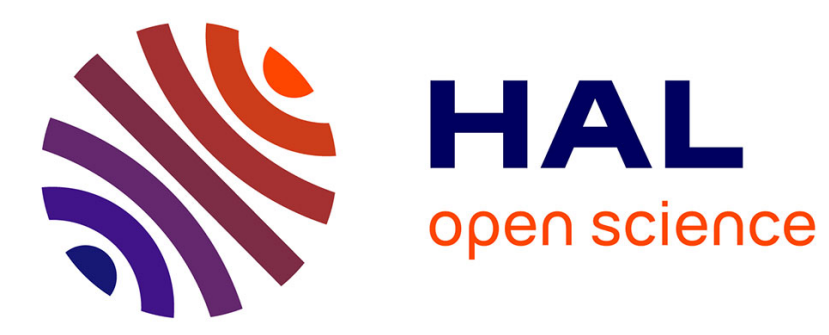

\title{
Organizing principles for vegetation dynamics
}

Oskar Franklin, Sandy Harrison, Roderick Dewar, Caroline E Farrior, Åke Brännström, Ulf Dieckmann, Stephan Pietsch, Daniel Falster, Wolfgang Cramer, Michel Loreau, et al.

\section{- To cite this version:}

Oskar Franklin, Sandy Harrison, Roderick Dewar, Caroline E Farrior, Åke Brännström, et al.. Organizing principles for vegetation dynamics. Nature Plants, 2020, 6 (5), pp.444-453. 10.1038/s41477020-0655-x . hal-02615052

\section{HAL Id: hal-02615052 https://hal.science/hal-02615052}

Submitted on 29 May 2020

HAL is a multi-disciplinary open access archive for the deposit and dissemination of scientific research documents, whether they are published or not. The documents may come from teaching and research institutions in France or abroad, or from public or private research centers.
L'archive ouverte pluridisciplinaire HAL, est destinée au dépôt et à la diffusion de documents scientifiques de niveau recherche, publiés ou non, émanant des établissements d'enseignement et de recherche français ou étrangers, des laboratoires publics ou privés. 


\title{
Organizing principles for vegetation dynamics
}

\author{
Oskar Franklin ${ }^{1,2} \llbracket$, Sandy P. Harrison ${ }^{3}{ }^{3}$, Roderick Dewar ${ }^{4,5}$, Caroline E. Farrior ${ }^{6}$, Åke Brännström ${ }^{1,7}$, \\ Ulf Dieckmann ${ }^{1,8}$, Stephan Pietsch', Daniel Falster ${ }^{10}{ }^{9}$, Wolfgang Cramer ${ }^{10}{ }^{10}$, Michel Loreau ${ }^{11}$, \\ Han Wang ${ }^{12}$, Annikki Mäkelä13, Karin T. Rebel ${ }^{14}$, Ehud Meron ${ }^{15,16}$, Stanislaus J. Schymanski ${ }^{17}$, \\ Elena Rovenskaya1, Benjamin D. Stocker (10) 18,19, Sönke Zaehle ${ }^{20}{ }^{20}$, Stefano Manzoni ${ }^{21,22}$, \\ Marcel van Oijen $\mathbb{D}^{23}$, lan J. Wright $\mathbb{D}^{24}$, Philippe Ciais ${ }^{25}$, Peter M. van Bodegom ${ }^{26}$, \\ Josep Peñuelas (10) 19,27, Florian Hofhansl (10), Cesar Terrer (iD ${ }^{28}$, Nadejda A. Soudzilovskaia ${ }^{26}$, \\ Guy Midgley ${ }^{29}$ and I. Colin Prentice ${ }^{12,24,30}$
}

Plants and vegetation play a critical—but largely unpredictable-role in global environmental changes due to the multitude of contributing processes at widely different spatial and temporal scales. In this Perspective, we explore approaches to master this complexity and improve our ability to predict vegetation dynamics by explicitly taking account of principles that constrain plant and ecosystem behaviour: natural selection, self-organization and entropy maximization. These ideas are increasingly being used in vegetation models, but we argue that their full potential has yet to be realized. We demonstrate the power of natural selection-based optimality principles to predict photosynthetic and carbon allocation responses to multiple environmental drivers, as well as how individual plasticity leads to the predictable self-organization of forest canopies. We show how models of natural selection acting on a few key traits can generate realistic plant communities and how entropy maximization can identify the most probable outcomes of community dynamics in space- and time-varying environments. Finally, we present a roadmap indicating how these principles could be combined in a new generation of models with stronger theoretical foundations and an improved capacity to predict complex vegetation responses to environmental change.

$\checkmark$ egetation dynamics involves processes operating at widely different spatial and temporal scales, from stomatal opening and closing (minutes to days, at the leaf level) to biome shifts (decades to centuries, across entire continents). Tremendous research efforts have been devoted to understanding and predicting how plant processes and functional traits of individuals combine to determine the structure, function and dynamics of vegetation on larger scales. To integrate process understanding from different disciplines, dynamic vegetation models (DVMs) have been developed that combine elements from plant biogeography, biogeochemistry, plant physiology, forest ecology and micrometeorology.
The best-known DVMs, dynamic global vegetation models (DGVMs), have found a wide field of application, including assessments of land-atmosphere carbon, water and trace gas exchanges; water resources; impacts of environmental change on plants and ecosystems; land management; and feedbacks from vegetation changes to regional and global climates ${ }^{1,2}$. DVMs have also been applied on local scales for testing of ecological hypotheses and to answer practical questions in forest management and agriculture. All DVMs are based on the assumption of universally valid processes, which, in principle, enable them to make predictions under conditions outside the range of observations used for model development.

IInternational Institute for Applied Systems Analysis, Laxenburg, Austria. ${ }^{2}$ Department of Forest Ecology and Management, Swedish University of Agricultural Sciences, Umeå, Sweden. ${ }^{3}$ Department of Geography and Environmental Science, University of Reading, Reading, UK. ${ }^{4}$ Plant Sciences Division, Research School of Biology, The Australian National University, Canberra, Australia. ${ }^{5}$ Institute for Atmospheric and Earth System Research/Physics, University of Helsinki, Helsinki, Finland. ${ }^{6}$ Department of Integrative Biology, University of Texas at Austin, Austin, TX, USA. ${ }^{7}$ Department of Mathematics and Mathematical Statistics, Umeå University, Umeå, Sweden. ${ }^{8}$ Department of Evolutionary Studies of Biosystems, The Graduate University for Advanced Studies (Sokendai), Hayama, Japan. ${ }^{9}$ Evolution and Ecology Research Centre, School of Biological, Earth and Environmental Sciences, University of New South Wales, Sydney, New South Wales, Australia. ${ }^{10}$ Institut Méditerranéen de Biodiversité et d'Ecologie Marine et Continentale (IMBE), Aix Marseille Université, CNRS, IRD, Avignon Université, Technopôle Arbois-Méditerranée, Aix-en-Provence, France. "'Centre for Biodiversity, Theory, and Modelling, Theoretical and Experimental Ecology Station, CNRS, Moulis, France. ${ }^{12}$ Ministry of Education Key Laboratory for Earth System Modeling, Department of Earth System Science, Tsinghua University, Beijing, China. ${ }^{13}$ Forest Sciences, University of Helsinki, Helsinki, Finland. ${ }^{14}$ Copernicus Institute of Sustainable Development, Environmental Sciences, Faculty of Geosciences, Utrecht University, Utrecht, The Netherlands. ${ }^{15}$ Blaustein Institutes for Desert Research, Ben-Gurion University of the Negev, Sede Boqer Campus, Israel. ${ }^{16}$ Department of Physics, Ben-Gurion University of the Negev, Be'er Sheva, Israel. ${ }^{17}$ Department of Environmental Research and Innovation, Luxembourg Institute of Science and Technology, Esch-sur-Alzette, Luxembourg. ${ }^{18}$ Department of Environmental Systems Sciences, ETH Zurich, Zurich, Switzerland. ${ }^{19} \mathrm{CREAF}$, Cerdanyola del Vallès, Spain. ${ }^{20}$ Biogeochemical Integration Department, Max Planck Institute for Biogeochemistry, Jena, Germany. ${ }^{21}$ Department of Physical Geography, Stockholm University, Stockholm, Sweden. ${ }^{22}$ Bolin Centre for Climate Research, Stockholm, Sweden. ${ }^{23}$ Centre for Ecology and Hydrology (CEH-Edinburgh), Bush Estate, Penicuik, UK. ${ }^{24}$ Department of Biological Sciences, Macquarie University, North Ryde, New South Wales, Australia. ${ }^{25}$ Laboratoire des Sciences du Climat et de I'Environnement, CEA CNRS UVSQ, Gif-sur-Yvette, France. ${ }^{26}$ Environmental Biology Department, Institute of Environmental Sciences, CML, Leiden University, Leiden, The Netherlands. ${ }^{27} \mathrm{CSIC}$, Global Ecology Unit CREAF-CSIC-UAB, Bellaterra, Spain. ${ }^{28}$ Physical and Life Sciences Directorate, Lawrence Livermore National Laboratory, Livermore, CA, USA. ${ }^{29}$ Department Botany \& Zoology, Stellenbosch University, Stellenbosch, South Africa. ${ }^{30}$ AXA Chair of Biosphere and Climate Impacts, Department of Life Sciences, Imperial College London, Silwood Park Campus, Ascot, UK. 凶e-mail: franklin@iiasa.ac.at 
DVMs have become more complex as a growing community of developers have striven to represent an ever-greater number of processes. However, additional complexity has rendered models dependent on providing values of an ever-increasing number of parameters, many of them poorly constrained by observations. This tendency has created a 'complexity trap', whereby increases in realism are offset by decreases in transparency, robustness and predictive power due to accumulation of uncertainty ${ }^{3}$. Moreover, important limitations of current DVMs have become apparent over the past decade. Predictions of carbon (C) fluxes and vegetation cover have been shown to differ greatly among state-of-the-art DGVMs (global DVMs), and these differences have not been reduced over time ${ }^{3-5}$. Possible underlying reasons for these divergences include contrasting or incomplete representations of nitrogen $(\mathrm{N})$ uptake, responses to soil moisture and mortality ${ }^{6-8}$. C allocation to different tissues is a key uncertainty in current DVMs ${ }^{9,10}$ due to a lack of consensus as to how plants and vegetation adjust to variations in the availability of different resources (such as water, $\mathrm{CO}_{2}$ and $\mathrm{N}$ ). For example, DVMs underestimate the ability of plants to enhance $\mathrm{N}$ uptake through increased below-ground $\mathrm{C}$ allocation and, at the same time, they overestimate changes in leaf $\mathrm{N}$ (ref. ${ }^{11}$ ), resulting in overly strong projected nutrient limitations on future $\mathrm{C}$ uptake ${ }^{12}$.

Plant diversity is another challenge for modelling. The effects of trait diversity have been evaluated in some DVMs using observed plant trait variation as an input ${ }^{13,14}$, and some models have addressed the generation and dynamics of trait diversity ${ }^{15,16}$. However, it remains a challenge to predict how diversity is maintained and may change over time. Including diversity in DVMs without sufficient understanding of its mechanistic basis risks further aggravating the complexity trap.

In summary, substantial progress has been made in understanding individual plant processes, and this understanding has been used to continually upgrade existing DVMs and to add new processes. While this approach improves predictions of current vegetation, the remaining problem (and the greater challenge) is to predict vegetation dynamics reliably in a changing environment. We argue here that consideration of three general organizing principlesnatural selection, self-organization and entropy maximization-can facilitate the development of more reliable vegetation models. These are not new ideas, but they have been explored, so far, primarily, in small-scale and theoretical studies. Some are already in use in prognostic DVMs, but their full potential for explaining vegetation dynamics has not yet been realized. Here, we aim to clarify the theoretical basis, and the potential and limitations, of these general organizing principles for improving our understanding of vegetation dynamics and our ability to predict vegetation change.

\section{The concept of organizing principles}

An organizing principle determines or constrains how components of a system, such as different plants in an ecosystem or different organs of a plant, behave together. Mathematically, an organizing principle can be envisaged as an additional equation added to a system of equations, allowing one or more previously unknown variables in the system to be determined, thereby reducing the uncertainty of the solution. We highlight three such principles that are valuable for understanding the complexity of organisms and ecosystems and, we argue, will help vegetation models to escape the complexity trap. The first is natural selection, operating on individuals (genotypes) to determine the traits of successful species and among species to determine community composition. The second is self-organization, whereby the interactions of system components (including individual plants) lead to a predictable system structure. The third is entropy maximization, a statistical selection principle which expresses the aggregated outcome of a large number of underlying stochastic processes subject to a small number of system-level constraints.

\section{Natural selection is a key source of predictability in plants}

All persisting plant traits and behaviours must have passed the filter of natural selection. Acting on individuals of a species, natural selection eliminates unfit or uncompetitive traits and trait combinations rapidly and effectively. Natural selection is thus the main reason why species do not possess arbitrary combinations of functionally significant traits. Acting on differences among species, natural selection is a driver of population and community dynamics. It generates strong relationships among traits, and correlations between traits and environment, that are not mandated by physical laws alone. Therefore-and despite the underlying complex interactions among organisms, communities and ecosystems-natural selection is a key source of predictability in biological systems. This simple and powerful idea allows models to predict more and require less input information (fewer uncertain parameters), which, ultimately, can improve both their predictive power and our scientific understanding of the patterns they describe.

Given that traits and community composition are subject to natural selection for increasing fitness, the resulting trait combinations may be predictable - they will be those that maximize fitness. Modelling approaches based on this optimality principle are a shortcut to predicting evolved traits and how they vary with environmental conditions (such as functional biogeography and phenotypic plasticity) without simulating the underlying evolutionary dynamics or physiological mechanisms through which optimality is achieved (note that optimality here refers to the eco-evolutionary optimality of plants, not the method of optimization used to estimate model parameters). Optimality reduces the amount of mechanistic detail needed in models and expands the range of conditions under which they can be applied without re-parameterization. It does not imply the existence of a specific physiological control mechanism (for example, hormones); optimality may be the result of bottom-up effects, such as local sink and source dynamics in each organ ${ }^{17}$, or the coordination of different processes ${ }^{18}$. Optimality hypotheses are thus concerned with the outcomes of plant mechanisms rather than the mechanisms themselves.

Optimality approaches to modelling often make use of economic concepts ${ }^{19}$, expressing the fitness proxy and the functional traits (FTs) optimized in terms of costs and benefits in a common currency (usually C). Thus, the optimality criterion is $\max$ (fitness proxy $(\mathrm{FTs})=$ benefits $(\mathrm{FTs})$ - costs (FTs)) with respect to FTs (Fig. 1; Supplementary Table 1). The fitness function implicitly integrates the effect of all processes and, therefore, does not have to be calibrated for different conditions or species. This property makes it well suited to address complex plant processes such as $\mathrm{C}$ allocation, which regulates, for example, how plants respond to increasing atmospheric $\mathrm{CO}_{2}$ concentration in the presence of other resource limitations. An optimality hypothesis stating that trees maximize net biomass increment and reproduction explains the interacting effects of elevated $\mathrm{CO}_{2}$ and $\mathrm{N}$ availability on tree growth and allocation, as observed in free air $\mathrm{CO}_{2}$ enrichment (FACE) experiments ${ }^{20,21}$ (Fig. 1). Maximization of a related fitness proxy also explains water use responses to elevated $\mathrm{CO}_{2}$ in FACE experiments ${ }^{22}$. The optimality hypothesis, stating that plants minimize the combined $\mathrm{C}$ costs of maintaining photosynthetic capacity and supporting water transport, explains a global pattern of variation among biomes in leaf $\mathrm{CO}_{2}$ uptake properties, requiring only two parameters that are common to all $\mathrm{C}_{3}$ plants $^{23,24}$ (Fig. 2).

Despite the power of eco-evolutionary optimality approaches to explain a wide range of observed phenomena (Supplementary Table 1), only a few have been applied in prognostic DVMs (for example, DGVMs): notably, formulations of optimal stomatal conductance $^{25-29}$ and leaf-level $\mathrm{N}$ allocation ${ }^{30}$. Optimal $\mathrm{C}$ allocation has been addressed in a prognostic DVM, not in terms of optimal acclimation (as in Fig. 1) but rather as an outcome of competition between different plant types, each with a pre-determined C allocation strategy ${ }^{31}$. 

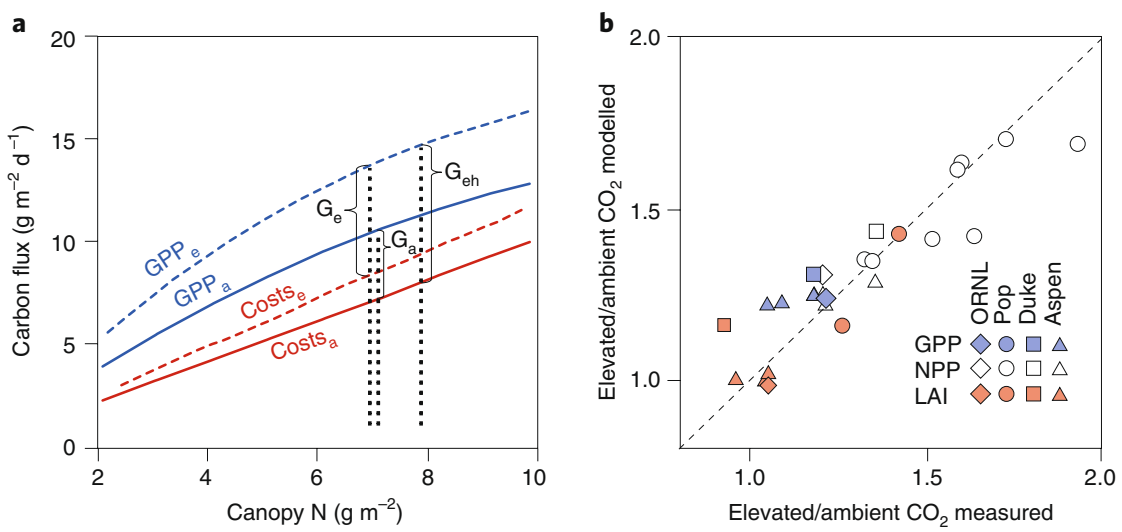

Fig. 1 | Optimality model of $\mathrm{CO}_{2}$ and $\mathrm{N}$ availability effects in FACE experiments. $\mathbf{a}$, The hypothesis is that trees optimize canopy $\mathrm{N}$ (vertical dashed lines) by maximizing net $\mathrm{C}$ gain ( $\mathrm{G}=\mathrm{GPP}$ - costs), where costs are carbon costs for maintaining the canopy (respiration + leaf and root turnover). Elevated $\mathrm{CO}_{2}$ (subscript e) increases GPP compared to ambient $\mathrm{CO}_{2}$ (subscript a), causing a potential large increase in optimal canopy $\mathrm{N}$ and net $\mathrm{C}$ gain $\left(\mathrm{G}_{\text {eh }}\right.$ ), which is not realized due to a simultaneous increase in $C$ costs per $N$ uptake (due to soil $N$ limitation), resulting in a smaller net effect $\left(G_{e}\right)$. $\mathbf{b}, M_{0}$.elled versus measured $\mathrm{CO}_{2}$ effects on productivity (GPP and NPP) and leaf area index (LAI) in forest FACE experiments with sweetgum (ORNL), loblolly pine (Duke), poplar (Pop) and aspen. $r^{2}=0.83$. Adapted from ref. ${ }^{20}$.

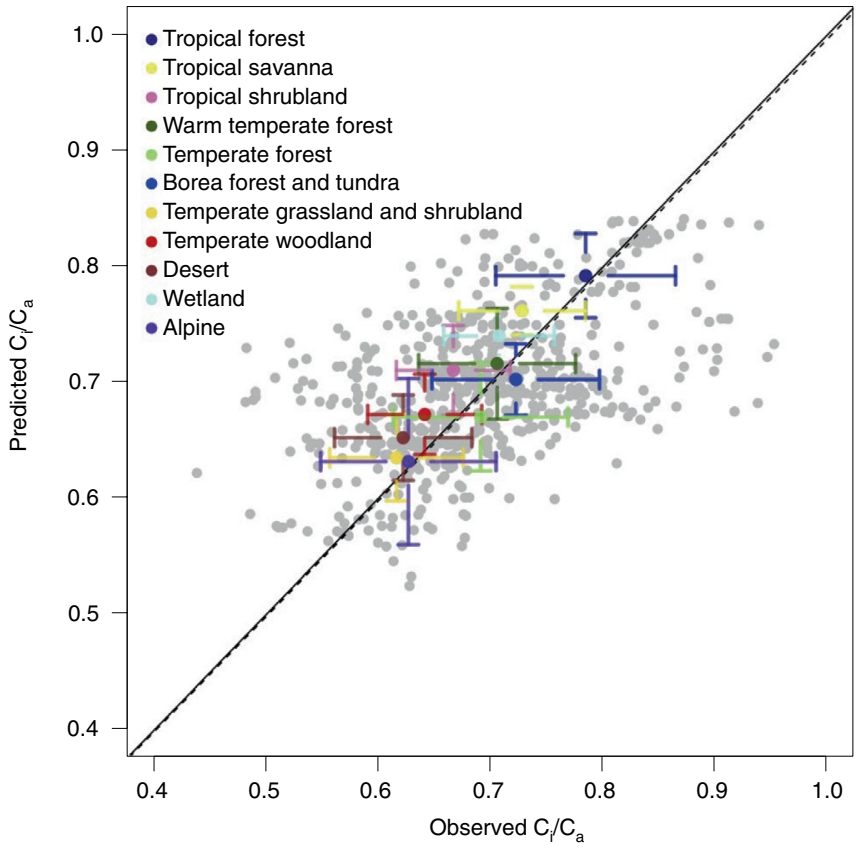

Fig. $2 \mid \mathrm{CO}_{2}$ uptake parameters predicted by an optimality principle. Using uniform parameters in conjunction with a cost-minimizing optimality hypothesis, a theoretical model predicts the ratio of leaf-internal to ambient $\mathrm{CO}_{2}\left(\mathrm{C}_{\mathrm{i}} / \mathrm{C}_{\mathrm{a}}\right)$ - a key index of leaf-level $\mathrm{C}$ and water exchangeacross the world's biomes ${ }^{23}$. The inputs are growing season temperature, vapour pressure deficit and elevation. Observations (based on leaf $\delta^{13} \mathrm{C}$ data) are compared with model predictions. Means and standard deviations are indicated for each biome. Although there is considerable unexplained variation among individual plants (grey points, $r^{2}=0.26$ ), biome means are well predicted by the model $\left(r^{2}=0.72\right)$. The continuous line represents the regression line (constrained to pass through the origin); the dashed line represents the $1 / 1$ line.

It is not straightforward to introduce optimal allocation in existing DGVMs because it requires a rethinking of the model structure from a sequential $\mathrm{C}$ flux from one compartment to the next to a linked regulation of leaves, stem and roots based on the costs and benefits of all of the limiting resources. However, in addition to this technical challenge, some conceptual issues may have hampered the application of optimality in prognostic DVMs.

One argument against the optimality approach is that optimality in a variable environment may never be reached ${ }^{32}$. This issue, however, calls for analysis of the appropriate temporal and spatial scale of the fitness proxies and the environmental variables and vegetation responses analysed ${ }^{22}$. At the leaf scale, the cost efficiency of leaf photosynthesis in terms of water and $C$ use has been used as a fitness proxy to predict regulation of stomatal conductance ${ }^{33-35}$. At the whole-plant scale, maximization of fitness proxies related to plant production has been used to predict $\mathrm{CO}_{2}$ uptake, root distributions $^{36-38}$, C allocation ${ }^{39}$ and tree height ${ }^{40}$. Organ-scale optimality, such as vertical leaf $\mathrm{N}$ distribution, can be nested within whole-plant optimality, such as whole-tree $\mathrm{N}$ and $\mathrm{C}$ allocation ${ }^{21}$. By including survival in the fitness proxy, optimality models can address forest $\mathrm{C}$ storage under elevated $\mathrm{CO}_{2}$ and water limitation ${ }^{41}$ and explain patterns and relationships of growth rate, mortality, wood density and drought response in trees ${ }^{42}$.

Another conceptual issue is a perceived conflict between optimality and the evolutionarily stable strategy (ESS), where ESS refers to the combination of trait values that emerges from competition among alternative strategies ${ }^{32,43}$. Based on game theory, it has been argued that evolution does not result in optimal solutions because the winning strategy in competition with others (the ESS) is not the same as the optimal strategy in the absence of competitors. However, this apparent conflict disappears if (i) optimality is defined at the individual level and (ii) the impact of competition is included in the definition of the biotic environment. This is naturally done in individual-based models, but can also be done in stand-based models, for example, by maximizing height growth as the winning strategy under competition for light ${ }^{44}$ or by explicitly modelling competition for light and nutrients ${ }^{39,40}$, water ${ }^{45}$ or mycorrhizal $\mathrm{N}$ supply ${ }^{46}$. Competition can have large effects on optimal behaviour. For example, competition for water reduces the benefits of saving water, leading to an optimal stomatal behaviour that differs from what would be optimal in the absence of competition ${ }^{47}$.

An important, but so far little-studied, question is to what extent trait variation along environmental gradients is due to phenotypic plasticity (acclimation within individuals) or genotypic differentiation. Traits differ in this respect ${ }^{48-50}$, and the difference is critical for the time scale of changes, as trait acclimation is faster than mean-trait changes due to shifts in community composition or 
genetic (or epigenetic) evolution. Although often lumped together in observational studies, plasticity is not equivalent to intraspecific variation because the latter may also include non-plastic (genetic) variation. While plastic traits acclimate to the current environment, genetic variation has been shaped by the whole evolutionary history, which is significantly more challenging to represent and makes it precarious to predict non-plastic traits from the plant's current local environment. However, some inter-relationships among traits (rather than trait versus environment) may be more predictable across variable environments, as indicated by trait economics spectra ${ }^{51-53}$. These relationships can be used to test optimality hypotheses, which can explain the mechanisms underlying trait relationships $s^{54,55}$ and can be used to predict how trait relationships vary across environments, in time as well as in space.

Fitness-based optimality is well-defined only at the individual level and usually predicts a single optimal strategy (a set of traits defining a plant type) for a given environment. Although real communities usually consist of many coexisting types, the single optimal strategy may be a good first-order approximation of the dominant plant type in a given environment. For example, a model that postulates that plants optimize the proportions of leaf, stem and root growth to compete with neighbours for $\mathrm{N}$ and $\mathrm{C}$ (resulting in an ESS) successfully reproduces observed global distributions of primary production and the allocation of $\mathrm{N}$ and $\mathrm{C}$ to leaves, stems and roots $^{56}$. This finding suggests that maximization of individual competitiveness for resources is a useful optimality principle to explain the dominant vegetation type and traits in a given environment. It may also be possible to use an optimality approach to address diversity by generating a range of alternative optimal strategies ${ }^{57}$. An advantage of the optimality approach compared to empirical community-mean traits approaches, for example $e^{58}$, is that the fitness function implicitly accounts for covariation among traits ${ }^{59,60}$.

In summary, eco-evolutionary optimality is a powerful concept to predict plant traits as a function of environmental conditions, especially for plastic processes, such as $\mathrm{C}$ and $\mathrm{N}$ allocation, which represent a weak point in predictive DVMs ${ }^{61}$. There is considerable potential to use optimality hypotheses to understand how and why different plant traits co-vary and to apply them to improve predictions of how trait values and species distributions respond to environmental change.

\section{Natural selection generates functional diversity}

Plant-level optimality concepts help in predicting a single (or dominant) strategy or plant type in a given environment, but they do not predict biodiversity within a site ( $\alpha$-diversity). For vegetation dynamics, functional diversity-variation in functional traits among the plants in a community-is the most relevant aspect of biodiversity $^{62}$. Natural selection drives the evolution of traits and community dynamics by operating on functional diversity. The inability of many current DVMs to account realistically for functional diversity has been shown to cause underestimation of local acclimation and adaptation ${ }^{63}$, artificial threshold behaviour ${ }^{64,65}$ and underestimation of the resilience of vegetation to environmental change $^{14}$. Functional trait diversity has been included as an input in a tropical forest model to improve its predictions of ecosystem processes $^{13,14}$, but this approach does not address the generation and maintenance of diversity. Diversity-generating approaches were pioneered in a simulation of the large-scale biogeography of marine phytoplankton ${ }^{66}$ and have been applied to theoretical analysis of vegetation dynamics ${ }^{67,68}$ and even the prognostic modelling of tropical ecosystems (aDGVM2 (refs. $\left.{ }^{15,16}\right)$ ). How best to represent functional diversity in DVMs nonetheless remains an open question.

Functional diversity can be understood as the outcome of two interacting effects: environmental filtering by the abiotic environment determines where a plant can potentially survive (the fundamental niche), while biotic interactions determine which plants can persist together (the realized niche). Environmental filtering is relatively straightforward to model $^{69}$, but coexistence is much more difficult. One approach is to more-or-less explicitly model the process of natural selection to derive trait combinations (genotypes or species) corresponding to ESSs-that is, an ESS community that cannot be invaded by other strategies ${ }^{68,70}$. By embedding the process of natural selection within models, functional diversity becomes an emergent property of ecosystems, thereby avoiding the need to pre-specify trait combinations or the number of types or species within a model. This approach may provide a framework for addressing evolutionary adaptation to a changing climate ${ }^{71,72}$.

The community ESS concept provides a way to generate and test hypotheses on coexistence (mechanisms that prevent one species from out-competing another) that can be applied in predictive models. In such a model, successional processes involving size-structured competition for light and disturbance can maintain functional diversity in a plant community ${ }^{68}$. By allowing species to differentiate along two functional trade-offs, functional diversity is recovered despite the absence of any imposed environmental heterogeneity (Fig. 3). However, without disturbance and the process of growing from seed, diversity in this model disappears. It follows that successional processes and individual dynamics need to be included in order to maintain diversity in vegetation models. Recent DVMs with explicit demography ${ }^{31,73,74}$ could thus be further developed into DVMs able to generate and maintain realistic functional diversity (diversity-enabled models).

However, while the diversity-enabled models are advancing the science of vegetation dynamics, developing them into prognostic tools poses additional challenges compared to traditional DVMs, such as the testing and calibration of diversity-maintaining mechanisms. In particular, the predictive ability of diversity-enabled models is potentially limited by the set of traits and coexistence mechanisms that are accounted for. In addition to trade-offs between costs and benefits of traits linked to resource (light) competition discussed above $^{68}$, there are many potential mechanisms of coexistence, involving resources, natural enemies, spatial heterogeneity and temporal variability ${ }^{75,76}$, making species coexistence a high-dimensional problem ${ }^{77}$. Complementarity-the idea that more species can use the total resources more completely-has been shown to reduce competition and promote coexistence in theoretical and empirical studies ${ }^{75,78-80}$, and deserves more attention in DVMs. Explaining the basis and roles of biodiversity has long been a central interest among theoretical and empirical ecologists ${ }^{81}$. It is now also becoming critical for DVMs.

\section{Self-organization simplifies forest structure}

While plant processes and behaviours originate at the level of individuals that are subject to natural selection and environmental constraints, the collective actions of individuals also drive patterns and processes that can provide organizing principles at the ecosystem level. For example, the collective spatial behaviour of plants gives rise to patterns in vegetation structure that provide both scientific insights and possible ways to reduce model complexity.

In forests, the plasticity of stem angles, leading to the collective organization of crown layers, is an excellent example of self-organization at the ecosystem level. The most computationally intensive aspect of many forest models is the calculation of plant light availability based on all individuals' locations, heights and shapes $^{82,83}$. Despite their detail, however, individual-based models often do not produce realistic-looking forest stands. There are too many gaps, and the emergent 'jigsaw puzzle' canopy pattern is missing. The perfect plasticity approximation (PPA) was developed to correct the problems of both computational intensity and unrealistic canopy patterns. The PPA is based on the observation that individuals can move their crowns horizontally towards sunlight (phototropism), which leads to a simple pattern (Fig. $4 \mathrm{a}-\mathrm{c}$ ): 

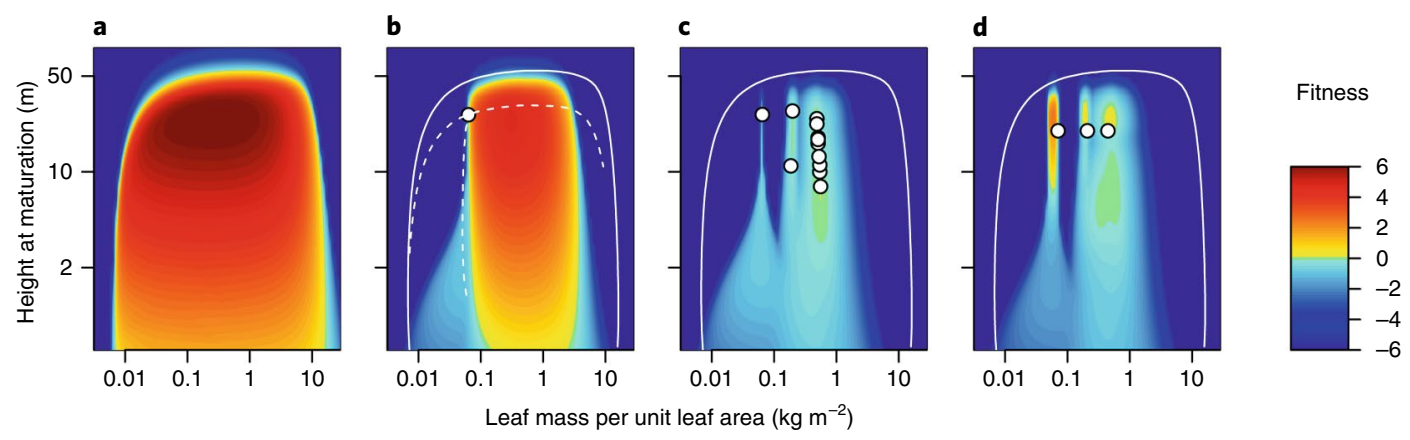

Fig. 3 | Modelling diverse communities based on evolutionarily stable strategies. By modelling reproductive success in competition with existing types (white dots), ESS models estimate the fitness of potential invaders (coloured shading) and use this to guide community assembly. Here, species are allowed to vary in two traits, underpinned by physiological trade-offs. a, Initially, a wide variety of trait combinations have positive fitness and could establish. b. Through directional selection, any single species is driven towards a local evolutionary attractor. However, this single species cannot prevent the invasion of other types if regions of positive fitness occur elsewhere in trait space. c, Through repeated rounds of mutation and selection, an ESS trait mixture may be established-that is, existing residents all have positive abundance while fitness is zero or negative elsewhere. The ESS trait mixture represents a prediction for the system diversity. d, In traditional models with pre-specified trait combinations, species may coexist but are not evolutionarily stable - that is, they could be invaded if new plant types were allowed into the system. In each panel, the solid white line delimits trait combinations that are not viable even in the absence of any competition (pure environmental filtering, as indicated in $\mathbf{a}$ ). In $\mathbf{b}$, the dashed white line shows the evolutionary attractors for each trait when allowed to evolve in isolation ${ }^{68}$.

canopy trees fill the horizontal space and there is approximately one height above which individual crowns are sunlit and below which individuals are in the shade of those canopy trees ${ }^{84}$. There will be a single height of canopy closure, and information on the locations of stems is no longer needed to calculate access to light. A rule defined at the level of individual trees (the search for sunlight) thus leads to a simple, emergent pattern that greatly simplifies the modelling of forest stand dynamics ${ }^{85}$.

The PPA has made possible the analytical ESS analysis of allocation strategies and predictions of their variation across environmental gradients in temperate forests ${ }^{41,45,86}$. Although many tropical forests exhibit a different size structure, the same rule of phototropism, though with different growth rates for canopy trees and frequency of stand-level disturbance, predicts the emergent structure of tropical stands ${ }^{87}$.

\section{Self-organization generates predictable patterns at the landscape scale}

Spatial self-organization in a landscape is driven by feedbacks between vegetation and the environment. For example, when trees establish in grasslands, they shade and suppress light-demanding grasses, competitively favouring other trees and eventually stabilizing patches of forests ${ }^{88}$. Dryland landscapes provide a striking example of vegetation self-organization into regular spatial patterns (Fig. 4d) caused by positive feedbacks between local vegetation growth and water transport towards the growth location, by laterally extended roots, overland water flow or soil-water diffusion ${ }^{89}$. Water transport helps vegetation growth, and that growth, in turn, enhances the water transport. The emergence of these patterns can be represented in continuous or high-resolution spatially explicit models, which reveal that the underlying positive feedback loop is a common organizing principle for spatial patterns across different locations and systems. Spatial self-reorganization in response to reduced rainfall slows desertification and results in successive state transitions to patterns of lower productivity (Fig. 4b) rather than in abrupt, direct collapse to bare soil ${ }^{90,91}$. Vegetation patterning can also promote species coexistence and help mitigate biodiversity loss ${ }^{91,92}$. However, this process is missing in general prognostic DVMs, perhaps due to the difficulty of representing spatial feedbacks in these spatially discrete (cell- or gap-based) models. However, the regularity of the patterns across rainfall gradients suggests that it may be possible to find universal approximations of their impacts, such as scaling relationships between fraction of vegetation cover and NPP or biomass ${ }^{93}$. Such a relationship could readily be incorporated in large-scale DGVMs or land-surface models to account for the larger- scale impacts of fine-scale spatial feedbacks without modelling these explicitly.

\section{Using entropy maximization to make order from chaos}

Ecosystems are complex systems with multiple interacting organisms and processes, yet there are obvious patterns in their macroscopic features, such as the emergence of biomes and their global relationships to macroclimatic patterns. This duality echoes the situation in physics where, for example, reproducible relationships among the pressure, temperature and volume of a large assembly of molecules emerge from the chaos of the underlying molecular collisions. The principle of maximum entropy (MaxEnt) ${ }^{94}$ has proved successful in predicting those relationships from a statistical perspective, as the most likely outcome of the underlying microscopic variables treated as random noise within the imposed experimental constraints (for example, fixed volume and temperature). MaxEnt can be applied at many scales, but the most interesting from the point of view of vegetation dynamics is the ecosystem scale, where the aggregated behaviour of large numbers of interacting individuals may be treated stochastically within the limits imposed by community-level environmental constraints (such as the constraint that community resource use must equal resource availability). Stochasticity means that many ecosystem states can correspond to the same resource use (constraint). MaxEnt predicts the probability of each state based on the number of ways it can be realized. Thus, in contrast to both deterministic process-based models and empirical species distribution models, MaxEnt applied in this way does not ignore stochastic factors but rather accounts for their effects.

The description of community resource use (for example, water or $\mathrm{N}$ ) within resource availability constraints requires some underlying biology to be modelled deterministically. MaxEnt enables us to test the assumed division between stochastic drivers (treated as random noise) and deterministic drivers, or mechanisms (treated as constraints). Agreement between MaxEnt predictions and observations indicates that the correct distinction has been identified; disagreement signals missing constraints or mechanisms. Extension to more than one resource constraint is straightforward. 

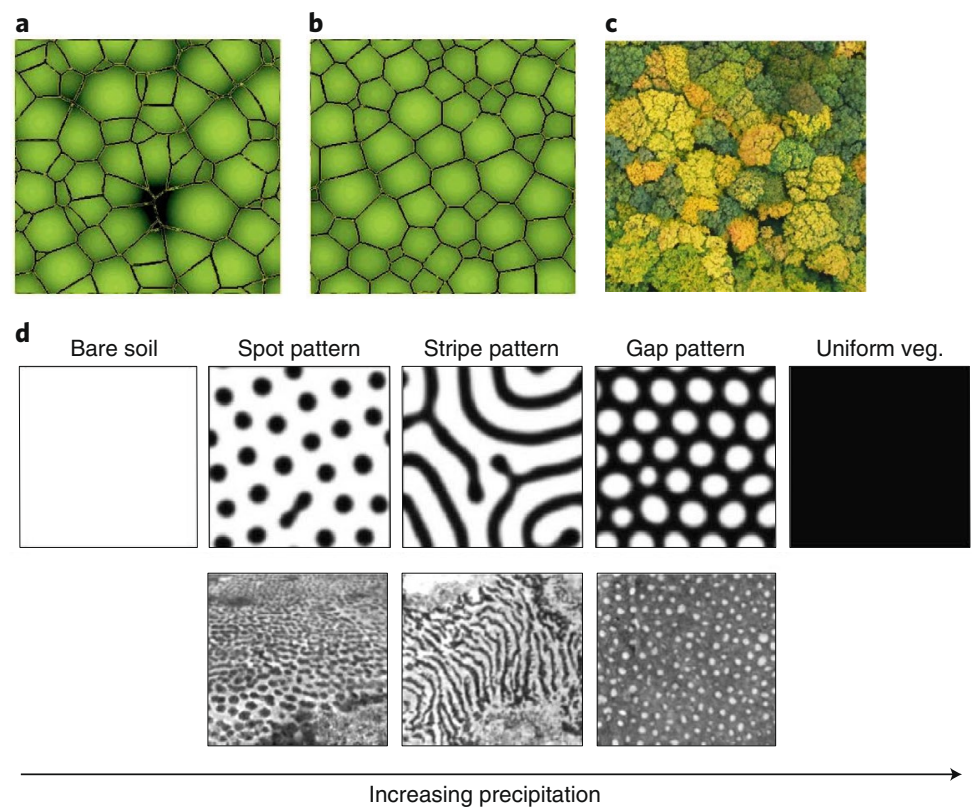

Fig. 4 | Spatial self-organization in ecosystems. a-c, Individual-level phototropism leads to emergent regularity in forest crown height and size. Tree crowns in a forest seen from above. $\mathbf{a}$, A forest dynamics model without phototropism ${ }^{84}$. b. The same forest dynamics model with individual phototropism (individuals allowed a maximum of $5^{\circ}$ lean in their trunks). Brightness indicates the height of the canopy. Note with phototropism, canopy height and crown size are more regular. c, Image of a near-natural forest in the Hainich National Park, Germany. Panels $\mathbf{a}$ and $\mathbf{b}$ are adapted from ref. ${ }^{84}$, and $\mathbf{c}$ is reproduced from ref. ${ }^{103}$. d, Spatial self-organization in dry lands. Typical sequence of vegetation patterns along a rainfall gradient. Modelled (upper panels) and observed (lower panels) are reproduced from ref. ${ }^{91}$. veg., vegetation.

An illustrative example is the use of MaxEnt to predict statistical patterns of tree-grass distribution over large areas of tropical savannas across a gradient in water availability ${ }^{95}$. The key constraint was assumed to be the mean annual community-scale water balance (evapotranspiration $=$ water availability). A simple hierarchy of water use was assumed (trees $>$ grasses $>$ bare ground). The broad agreement between predictions and satellite-derived data (Fig. 5) suggests that a valid deterministic driver had been identified. Other processes, which include disturbances by fire and herbivory, contribute to the statistical spread of the data in Fig. 5 at any given water availability and can be treated as random noise that has no systematic effect on the mean trends.

An important caveat is that, just as the laws of probability only predict the most likely frequency distribution of heads and tails in a long run of coin tosses and not the outcome of an individual toss, MaxEnt only predicts the most likely frequency distribution of treegrass cover fractions across many sites and not the tree-grass cover fractions at a given site (an individual data point in Fig. 5). The latter would require explicit representation of, and site-specific information about, other processes, such as fire history and herbivory.

In this example, the link between MaxEnt and the underlying biology occurs through the assumed water use rates $e_{\mathrm{i}}$ of each cover type, where ' $i$ ' represents the cover type (trees, grass or bare ground), which determine the community water use that appears in the water balance constraint. MaxEnt then predicts that the cover type with the highest or lowest value of $e_{\mathrm{i}}$ dominates at high or low water availability, respectively (Fig. 5). A natural generalization of this approach would be to replace assigned values of $e_{\mathrm{i}}$ by an eco-physiological model, $e(\mathrm{FTs})$, for the dependence of plant resource use on FTs and environmental conditions, such as climate. Then, at high or low resource availability, MaxEnt would predict a relative abundance distribution in trait space that follows the peaks or troughs of $e(\mathrm{FTs})$, respectively, thus establishing a link between diversity in FTs at the community level (the distribution) and optimal FTs (the expected values).
MaxEnt-based approaches could potentially be developed to incorporate stochastic effects on coexistence in DVMs and to identify the key deterministic drivers that generate and maintain diversity-an important challenge for understanding long-term vegetation dynamics.

\section{A roadmap for the use of organizing principles in vegetation modelling}

The three organizing principles discussed above could be combined in a hierarchical framework for vegetation modelling, from FTs, to species (or functional types) to stand structure and community composition (Fig. 6). Figure 6 represents a general framework within which current knowledge and future progress at different levels (plant, community and environment) can be integrated with help of the organizing principles. In the following sub-sections, we suggest in general terms how this could be done, maintaining essential realism-while avoiding the complexity trap of accumulating uncertainty and lack of model transparency-in a new generation of DVMs.

Defining plants by functional traits. Plant species (or functional types) in DVMs are defined in terms of FTs for which there is substantial variation among plants, measured values are available for many plants, and one or more functions are known. Our perspective implies more precise criteria for how to select and use FTs. First, the finding that only two underlying dimensions of variation explain $75 \%$ of the global variation in key FTs ${ }^{51}$ suggests that fewer FTs could be used compared to most current DVMs. Second, a shift is required from using trait measurements (for example, mean values for each functional type) directly in models towards their use to test and calibrate the underlying principles and constraints, such as optimality principles, that control trait variation ${ }^{32}$.

An efficient representation of species should be based on a few functionally important FTs that are as non-plastic (heritable) as possible (Fig. 6). Plastic traits that vary systematically with 

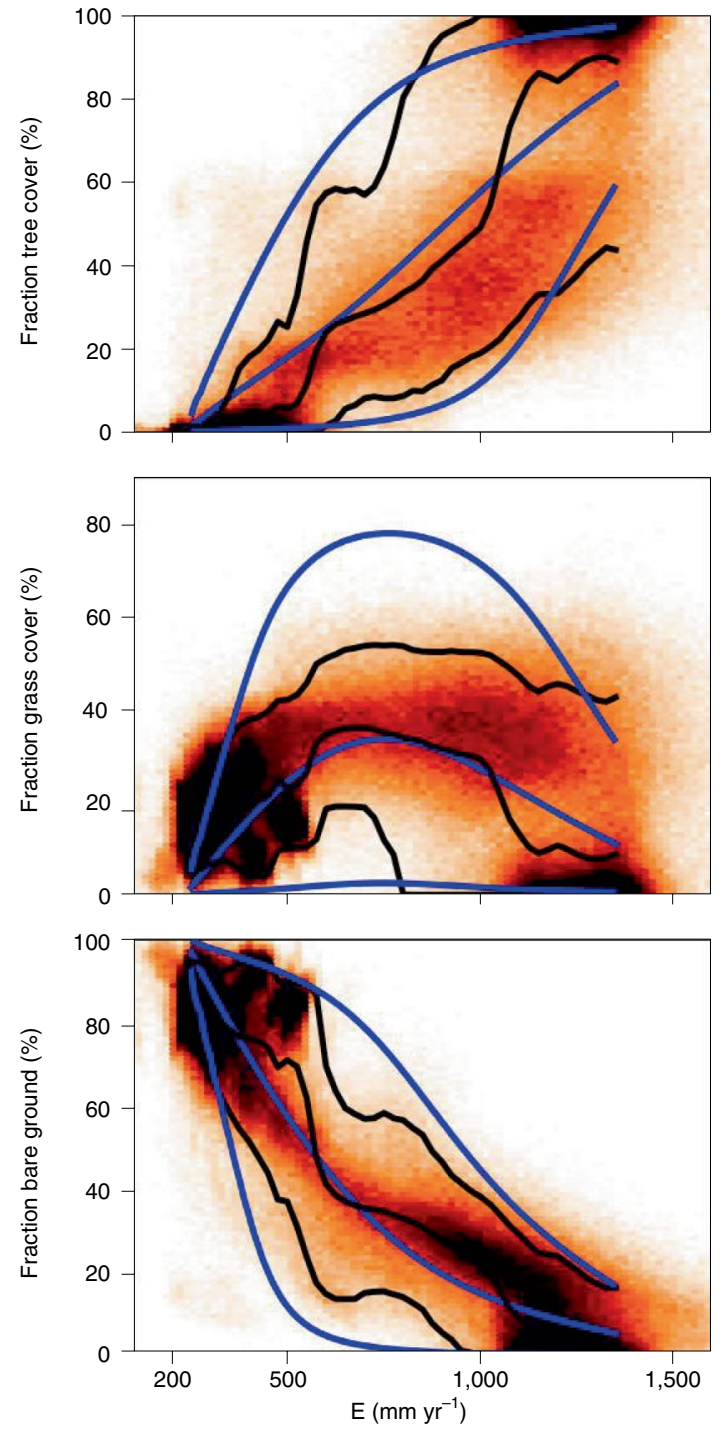

Fig. 5 | Vegetation distributions predicted by the principle of MaxEnt. Observed and modelled frequency distributions of tree, grass and bare ground cover fractions versus mean annual water availability (E) in tropical savannas at a $1 \mathrm{~km}^{2}$ resolution. The orange shading indicates the frequency histogram of satellite-based (MODIS) fractional cover estimates sampled from Africa, South America and Australia. Black curves from bottom to top indicate the 5th percentile, mean and 95th percentile of the observed sample frequency histogram versus $E$, respectively. Blue curves from bottom to top indicate the 5th percentile, mean and 95th percentile of the modelled frequency distributions versus $\mathrm{E}$, respectively. Adapted from ref. ${ }^{95}$.

environmental conditions, such as leaf/stem/root ratios, relative growth rates, height and photosynthetic capacity, should not be pre-determined but instead should be predicted based on optimality principles. Observed trait variation and function can be analysed in new ways that separate plasticity from other sources of trait variation $^{96}$. For example, SLA is commonly used to define species in terms of a mean value, although it varies strongly with environmental conditions, even within individuals ${ }^{97}$. To resolve this problem, SLA could be separated into a non-plastic maximal SLA and a plastic component to be determined by optimization. Optimization might not be possible or computationally feasible for all plastic FTs, but, instead, optimality can be approximated by continuous

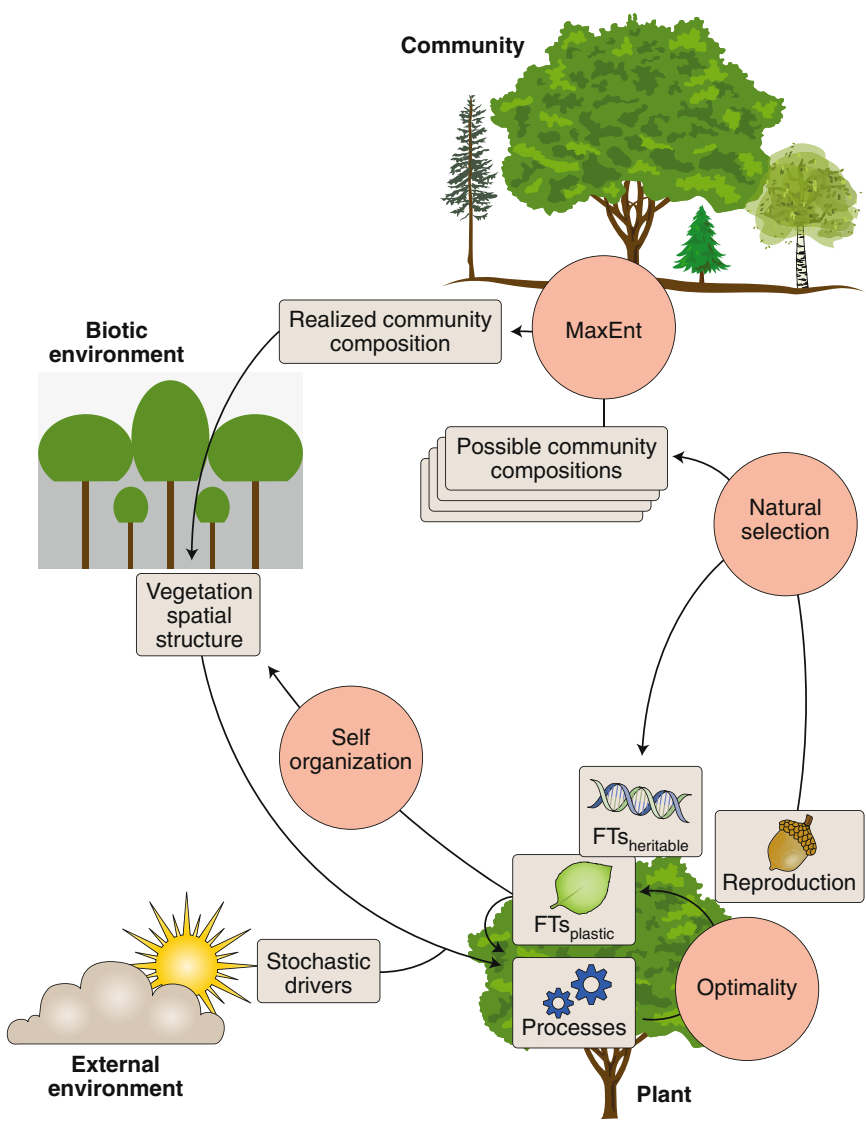

Fig. 6 | Framework for the use of organizing principles in vegetation modelling. The application of organizing principles (circles) helps predict (arrows) vegetation properties (boxes). Natural selection drives the evolution of species (or plant types) and their heritable functional traits, modelled as emergent ESSs. Natural selection is also the reason that phenotypic plasticity in response to environmental variation is predictable through fitness-proxy maximization (optimality). At the community level, collective self-organization among many plants results in predictable patterns of spatial structure at the stand level (for example, due to plasticity of stem angles in the perfect plasticity approximation). Self-organization influences the biotic environment, which, together with the abiotic (external) environment, feeds back on plant reproduction and survival-that is, the natural selection of community composition. Many different community compositions may be possible, and the most likely can be predicted by MaxEnt. The external environment includes abiotic factors and all other external drivers, including disturbance regimes.

adjustments in an optimal direction, as has been done for $\mathrm{LAI}^{98}$ and stomatal conductance ${ }^{36}$.

Once a set of non-plastic FTs have been identified, observed inter-relationships between them (trait spectra) could be used in two ways: (i) to constrain potential species in terms of possible (or more or less probable) trait combinations to generate potential species to select from when generating a community using a DVM with community dynamics or (ii), to evaluate community-ESS approaches that model the co-evolution of species and their FTs, such as the forest model by Falster et al. ${ }^{68}$

Modelling vegetation structure and competition. Self-organized spatial structures have strong effects on vegetation dynamics by both generating and reducing heterogeneity. The latter effect is used in the PPA to simplify models of light competition in forest canopies. The PPA appears well-suited to low-diversity canopies, whereas the PPA's binary light availability might be expected to lead 
to artificial exclusion of species with low shade tolerance in more diverse communities. However, such problems can be resolved by a sufficiently high spatial resolution in the critical canopy height ${ }^{87}$. Although further quantification of its limitations is still needed, adoption of the PPA in models of forest dynamics has also opened the door to computationally efficient representations of competition for light and succession in large-scale prognostic DVMs ${ }^{31,74}$.

While competition for below-ground resources can be readily modelled by assuming common pools of soil resources for all plants in a stand ${ }^{86}$, the validity of this 'perfect mixing' assumption is not well known. The actual spatial extent of competition for nutrients and water is not well understood despite potentially large implications for key processes such as root growth ${ }^{99}$, water use $\mathrm{e}^{47}$ and whole-plant growth ${ }^{39}$.

In summary, modelling schemes that assemble individuals into communities become far more tractable (analytically and computationally) when processes promoting self-organization are taken into account. To support this development further, quantitative evaluations of the accuracy of the PPA and other approximations of above- and below-ground vegetation structure and competition are strongly needed.

Dealing with the complexity of communities. DVMs that generate communities by modelling the natural selection process ${ }^{67,68}$ are referred to here as diversity-enabled models. Although their prognostic application has been limited so far ${ }^{15,16}$, diversity-enabled models offer an improved potential to predict long-term ecosystem dynamics under climate change, including biome shifts and the role of biodiversity in promoting ecosystem resilience. Complementing the species diversity in these models with individual plasticity could lead to novel insights in how plasticity and community dynamics interact and influence the rate of adaptation of vegetation to climate change, which is critical for projections of future vegetation processes and carbon balance ${ }^{7,100}$. The need to model both individual plasticity and community dynamics is highlighted by the observation that they sometimes drive site-mean values of FTs in opposite directions along environmental gradients ${ }^{101}$.

A critical question for the further development of diversityenabled models is whether the relevant coexistence mechanisms are included. An important, but often neglected, factor in this context is demographic and environmental stochasticity, which makes community composition unpredictable for any particular point in space and time. MaxEnt has been used to account for randomness in predicting community composition-that is, the abundance of each species-using mean trait values as site-level constraints ${ }^{102}$. A similar approach could be applied with a diversity-enabled DVM that represents the hypothesized coexistence mechanisms, with resource availabilities providing additional constraints. For any given set of resource availabilities there is stochastic variation in environmental variables and plant demography (for example, recruitment and mortality). Under realistic boundary conditions, therefore, a DVM can generate many communities with different species compositions. The mechanisms incorporated in the DVM, and the resource availabilities specified, influence the probability (or frequency) that a given community is generated. Based on the accumulated distribution of possible community compositions, MaxEnt can be used to find the most likely community composition (Fig. 6).

In conclusion, the principles and modelling approaches put forward here all address the same key challenge in the science of vegetation dynamics-how to make sense of complexity. During the initial development of DVMs in the 1980s, very few ecologists looked for general patterns in nature. Since then, many promising, but sometimes diverging, approaches have emerged. With the perspectives on organizing principles presented here, we aim to contribute to a coherent theoretical basis for explaining and predicting interactions among plants and their environment. This proposed framework also implies a key role for empirical research in testing model hypotheses and exploring vegetation patterns to generate new hypotheses. Based on the organizing principles, progress in the study of plant processes and traits can be put into a consistent theoretical framework to improve model robustness and transparency and avoid the complexity trap. This framework is required for a better understanding of vegetation dynamics and carbon cycling in a changing world.

Received: 31 July 2019; Accepted: 2 April 2020;

Published online: 11 May 2020

\section{References}

1. Prentice, I. C. \& Cowling, S. A. in Encyclopedia of Biodiversity 2nd edn (Ed. Levin, S. A.) 670-689 (Academic Press, 2013).

2. Fisher, J. B., Huntzinger, D. N., Schwalm, C. R. \& Sitch, S. Modeling the terrestrial biosphere. Annu. Rev. Env. Resour. 39, 91-123 (2014).

3. Prentice, I. C., Liang, X., Medlyn, B. E. \& Wang, Y. P. Reliable, robust and realistic: the three R's of next-generation land-surface modelling. Atmos. Chem. Phys. 15, 5987-6005 (2015).

4. Whitley, R. et al. Challenges and opportunities in land surface modelling of savanna ecosystems. Biogeosciences 14, 4711-4732 (2017).

5. Pugh, T. A. M. et al. A large committed long-term sink of carbon due to vegetation dynamics. Earths Future 6, 1413-1432 (2018).

6. Huang, Y., Gerber, S., Huang, T. \& Lichstein, J. W. Evaluating the drought response of CMIP5 models using global gross primary productivity, leaf area, precipitation, and soil moisture data. Global Biogeochem. Cy. 30, 1827-1846 (2016)

7. Walker, A. P. et al. Predicting long-term carbon sequestration in response to $\mathrm{CO}_{2}$ enrichment: how and why do current ecosystem models differ? Global Biogeochem. Cy. 29, 476-495 (2015).

8. Thurner, M. et al. Evaluation of climate-related carbon turnover processes in global vegetation models for boreal and temperate forests. Glob. Change Biol. 23, 3076-3091 (2017).

9. Xia, J., Yuan, W., Wang, Y.-P. \& Zhang, Q. Adaptive carbon allocation by plants enhances the terrestrial carbon sink. Sci. Rep. 7, 3341 (2017).

10. Montané, F. et al. Evaluating the effect of alternative carbon allocation schemes in a land surface model (CLM4.5) on carbon fluxes, pools, and turnover in temperate forests. Geosci. Model Dev. 10, 3499-3517 (2017).

11. Zaehle, S. et al. Evaluation of 11 terrestrial carbon-nitrogen cycle models against observations from two temperate Free-Air $\mathrm{CO}_{2}$ Enrichment studies. New Phytol. 202, 803-822 (2014).

12. Sulman, B. N. et al. Diverse mycorrhizal associations enhance terrestrial C storage in a global model. Global Biogeochem. Cy. 33, 501-523 (2019).

13. Fyllas, N. et al. Analysing Amazonian forest productivity using a new individual and trait-based model (TFS v. 1). Geosci. Model Dev. 7, 1251-1269 (2014)

14. Sakschewski, B. et al. Resilience of Amazon forests emerges from plant trait diversity. Nat. Clim. Change 6, 1032-1036 (2016).

15. Gaillard, C. et al. African shrub distribution emerges via a trade-off between height and sapwood conductivity. J. Biogeogr. 45, 2815-2826 (2018).

16. Langan, L., Higgins, S. I. \& Scheiter, S. Climate-biomes, pedo-biomes or pyro-biomes: which world view explains the tropical forest-savanna boundary in South America? J. Biogeogr. 44, 2319-2330 (2017).

17. Thornley, J. H. M. Modelling shoot:root relations: the only way forward? Ann. Bot. 81, 165-171 (1998).

18. Chen, J. L. \& Reynolds, J. F. A coordination model of whole-plant carbon allocation in relation to water stress. Ann. Bot. 80, 45-55 (1997).

19. Bloom, A. J. Plant economics. Trends Ecol. Evol. 1, 98-100 (1986).

20. Franklin, O. Optimal nitrogen allocation controls tree responses to elevated $\mathrm{CO}_{2}$. New Phytol. 174, 811-822 (2007).

21. Franklin, O. et al. Forest fine-root production and nitrogen use under elevated $\mathrm{CO}_{2}$ : contrasting responses in evergreen and deciduous trees explained by a common principle. Glob. Change Biol. 15, 132-144 (2009).

22. Schymanski, S. J., Roderick, M. L. \& Sivapalan, M. Using an optimality model to understand medium and long-term responses of vegetation water use to elevated atmospheric $\mathrm{CO}_{2}$ concentrations. AoB PLANTS 7, plv060 (2015).

23. Wang, H. et al. Towards a universal model for carbon dioxide uptake by plants. Nat. Plants 3, 734-741 (2017).

24. Bloomfield, K. J. et al. The validity of optimal leaf traits modelled on environmental conditions. New Phytol. 221, 1409-1423 (2019).

25. Xu, X., Medvigy, D., Powers, J. S., Becknell, J. M. \& Guan, K. Diversity in plant hydraulic traits explains seasonal and inter-annual variations of vegetation dynamics in seasonally dry tropical forests. New Phytol. 212, 80-95 (2016). 
26. Eller, C. B. et al. Modelling tropical forest responses to drought and El Niño with a stomatal optimization model based on xylem hydraulics. Philos. T. R. Soc. Lon. B 373, 20170315 (2018).

27. Kennedy, D. et al. Implementing plant hydraulics in the community land model, version 5. J. Adv. Model. Earth Sy. 11, 485-513 (2019).

28. De Kauwe, M. G. et al. A test of an optimal stomatal conductance scheme within the CABLE land surface model. Geosci. Model Dev. 8, 431-452 (2015).

29. Franks, P. J. et al. Comparing optimal and empirical stomatal conductance models for application in Earth system models. Glob. Change Biol. 24, 5708-5723 (2018).

30. $\mathrm{Xu}, \mathrm{C}$. et al. Toward a mechanistic modeling of nitrogen limitation on vegetation dynamics. PLoS ONE 7, e37914 (2012).

31. Weng, E. et al. Scaling from individual trees to forests in an Earth system modeling framework using a mathematically tractable model of height-structured competition. Biogeosciences 12, 2655-2694 (2015)

32. Fisher, R. A. et al. Taking off the training wheels: the properties of a dynamic vegetation model without climate envelopes, CLM4.5(ED). Geosci. Model Dev. 8, 3593-3619 (2015).

33. Medlyn, B. E. et al. Reconciling the optimal and empirical approaches to modelling stomatal conductance. Glob. Change Biol. 17, 2134-2144 (2011).

34. Manzoni, S., Vico, G., Palmroth, S., Porporato, A. \& Katul, G. Optimization of stomatal conductance for maximum carbon gain under dynamic soil moisture. Adv. Water Resour. 62, 90-105 (2013).

35. Dewar, R. et al. New insights into the covariation of stomatal, mesophyll and hydraulic conductances from optimization models incorporating nonstomatal limitations to photosynthesis. New Phytol. 217, 571-585 (2018).

36. Schymanski, S. J., Sivapalan, M., Roderick, M., Hutley, L. B. \& Beringer, J. An optimality-based model of the dynamic feedbacks between natural vegetation and the water balance. Water Resour. Res. 45, W01412 (2009).

37. Guswa, A. J. Effect of plant uptake strategy on the water-optimal root depth. Water Resour. Res. 46, W09601 (2010).

38. Yang, Y., Donohue, R. J. \& McVicar, T. R. Global estimation of effective plant rooting depth: implications for hydrological modeling. Water Resour Res. 52, 8260-8276 (2016).

39. Franklin, O. et al. Modeling carbon allocation in trees: a search for principles. Tree Physiol. 32, 648-666 (2012).

40. King, D. A. The adaptive significance of tree height. Am. Nat. 135, 809-828 (1990).

41. Farrior, C. E., Rodriguez-Iturbe, I., Dybzinski, R., Levin, S. A. \& Pacala, S. W. Decreased water limitation under elevated $\mathrm{CO}_{2}$ amplifies potential for forest carbon sinks. Proc. Natl Acad. Sci. USA 112, 7213-7218 (2015).

42. Franklin, O., Palmroth, S. \& Näsholm, T. How eco-evolutionary principles can guide tree breeding and tree biotechnology for enhanced productivity. Tree Physiol. 34, 1149-1166 (2014).

43. Hikosaka, K. \& Anten, N. P. R. An evolutionary game of leaf dynamics and its consequences for canopy structure. Funct. Ecol. 26, 1024-1032 (2012).

44. Valentine, H. T. \& Mäkelä, A. Modeling forest stand dynamics from optimal balances of carbon and nitrogen. New Phytol. 194, 961-971 (2012).

45. Farrior, C. E. et al. Resource limitation in a competitive context determines complex plant responses to experimental resource additions. Ecology 94 2505-2517 (2013).

46. Franklin, O., Näsholm, T., Högberg, P. \& Högberg, M. N. Forests trapped in nitrogen limitation - an ecological market perspective on ectomycorrhizal symbiosis. New Phytol. 203, 657-666 (2014).

47. Wolf, A., Anderegg, W. R. L. \& Pacala, S. W. Optimal stomatal behavior with competition for water and risk of hydraulic impairment. Proc. Natl Acad. Sci. USA 113, E7222-E7230 (2016).

48. Yang, J., Cao, M. \& Swenson, N. G. Why functional traits do not predict tree demographic rates. Trends Ecol. Evol. 33, 326-336 (2018).

49. Dong, N. et al. Leaf nitrogen from first principles: field evidence for adaptive variation with climate. Biogeosciences 14, 481-495 (2017).

50. Meng, T.-T. et al. Responses of leaf traits to climatic gradients: adaptive variation versus compositional shifts. Biogeosciences 12, 5339-5352 (2015).

51. Díaz, S. et al. The global spectrum of plant form and function. Nature 529, 167-171 (2016).

52. Wright, I. J. et al. The worldwide leaf economics spectrum. Nature $\mathbf{4 2 8}$, 821-827 (2004).

53. Reich, P. B. The world-wide 'fast-slow' plant economics spectrum: a traits manifesto. J. Ecol. 102, 275-301 (2014).

54. McMurtrie, R. E. \& Dewar, R. C. Leaf-trait variation explained by the hypothesis that plants maximize their canopy carbon export over the lifespan of leaves. Tree Physiol. 31, 1007-1023 (2011).

55. Maire, V. et al. Disentangling coordination among functional traits using an individual-centred model: impact on plant performance at intra- and inter-specific levels. PLoS ONE 8, e77372 (2013).
56. McNickle, G. G., Gonzalez-Meler, M. A., Lynch, D. J., Baltzer, J. L. \& Brown, J. S. The world's biomes and primary production as a triple tragedy of the commons foraging game played among plants. P. Roy. Soc. Lond. B-Biol. Sci. 283, 20161993 (2016).

57. Marks, C. O. The causes of variation in tree seedling traits: the roles of environmental selection versus chance. Evolution 61, 455-469 (2007).

58. van Bodegom, P. M., Douma, J. C. \& Verheijen, L. M. A fully traits-based approach to modeling global vegetation distribution. Proc. Natl Acad. Sci. USA 111, 13733-13738 (2014).

59. Laughlin, D. C. \& Messier, J. Fitness of multidimensional phenotypes in dynamic adaptive landscapes. Trends Ecol. Evol. 30, 487-496 (2015).

60. Clark, J. S. Why species tell more about traits than traits about species: predictive analysis. Ecology 97, 1979-1993 (2016).

61. Achat, D. L., Augusto, L., Gallet-Budynek, A. \& Loustau, D. Future challenges in coupled C-N-P cycle models for terrestrial ecosystems under global change: a review. Biogeochemistry 131, 173-202 (2016).

62. Tilman, D. et al. The influence of functional diversity and composition on ecosystem processes. Science 277, 1300-1302 (1997).

63. de Almeida Castanho, A. D. et al. Changing Amazon biomass and the role of atmospheric $\mathrm{CO}_{2}$ concentration, climate, and land use. Global Biogeochem. Cy. 30, 18-39 (2016).

64. Kleidon, A., Fraedrich, K. \& Low, C. Multiple steady-states in the terrestrial atmosphere-biosphere system: a result of a discrete vegetation classification? Biogeosciences 4, 707-714 (2007).

65. Lavorel, S. et al. in Terrestrial Ecosystems in a Changing World (eds Canadell, J. G. et al.) 149-164 (Springer, 2007).

66. Follows, M. J., Dutkiewicz, S., Grant, S. \& Chisholm, S. W. Emergent biogeography of microbial communities in a model ocean. Science 315, 1843-1846 (2007).

67. Scheiter, S., Langan, L. \& Higgins, S. I. Next-generation dynamic global vegetation models: learning from community ecology. New Phytol. 198, 957-969 (2013)

68. Falster, D. S., Brännström, Å., Westoby, M. \& Dieckmann, U. Multitrait successional forest dynamics enable diverse competitive coexistence. Proc. Natl Acad. Sci. USA 114, E2719-E2728 (2017).

69. Pavlick, R., Drewry, D. T., Bohn, K., Reu, B. \& Kleidon, A. The jena diversity-dynamic global vegetation model (JeDi-DGVM): a diverse approach to representing terrestrial biogeography and biogeochemistry based on plant functional trade-offs. Biogeosciences 10, 4137-4177 (2013).

70. Hofbauer, J. \& Sigmund, K. The Theory of Evolution and Dynamical Systems: Mathematical Aspects of Selection (Cambridge Univ. Press, 1988).

71. Franks, S. J., Sim, S. \& Weis, A. E. Rapid evolution of flowering time by an annual plant in response to a climate fluctuation. Proc. Natl Acad. Sci. USA 104, 1278-1282 (2007).

72. Jump, A. S. \& Peñuelas, J. Running to stand still: adaptation and the response of plants to rapid climate change. Ecol. Lett. 8, 1010-1020 (2005).

73. Medvigy, D., Wofsy, S. C., Munger, J. W., Hollinger, D. Y. \& Moorcroft, P. R. Mechanistic scaling of ecosystem function and dynamics in space and time: Ecosystem Demography model version 2. J. Geophys. Res. Biogeosci. 114, G01002 (2009).

74. Fisher, R. A. et al. Vegetation demographics in Earth System Models: a review of progress and priorities. Glob. Change Biol. 24, 35-54 (2018).

75. Loreau, M. From Populations to Ecosystems: Theoretical Foundations for a new Ecological Synthesis (MPB-46) (Princeton Univ. Press, 2010).

76. Adler, P. B., Fajardo, A., Kleinhesselink, A. R. \& Kraft, N. J. B. Trait-based tests of coexistence mechanisms. Ecol. Lett. 16, 1294-1306 (2013).

77. Clark, J. S. et al. Resolving the biodiversity paradox. Ecol. Lett. 10, 647-659 (2007).

78. Isbell, F. et al. Quantifying effects of biodiversity on ecosystem functioning across times and places. Ecol. Lett. 21, 763-778 (2018).

79. Cardinale, B. J. et al. Biodiversity loss and its impact on humanity. Nature 486, 59-67 (2012).

80. Craven, D. et al. Multiple facets of biodiversity drive the diversity-stability relationship. Nat. Ecol. Evol. 2, 1579-1587 (2018).

81. García-Palacios, P., Gross, N., Gaitán, J. \& Maestre, F. T. Climate mediates the biodiversity-ecosystem stability relationship globally. Proc. Natl Acad. Sci. USA 115, 8400-8405 (2018).

82. Weiner, J., Stoll, P., Muller-Landau, H. \& Jasentuliyana, A. The effects of density, spatial pattern, and competitive symmetry on size variation in simulated plant populations. Am. Nat. 158, 438-450 (2001).

83. Moorcroft, P. R., Hurtt, G. C. \& Pacala, S. W. A method for scaling vegetation dynamics: the ecosystem demography model (ED). Ecol. Monogr. 71, 557-586 (2001).

84. Strigul, N., Pristinski, D., Purves, D., Dushoff, J. \& Pacala, S. Scaling from trees to forests: tractable macroscopic equations for forest dynamics. Ecol. Monogr. 78, 523-545 (2008).

85. Purves, D. W., Lichstein, J. W., Strigul, N. \& Pacala, S. W. Predicting and understanding forest dynamics using a simple tractable model. Proc. Natl Acad. Sci. USA 105, 17018-17022 (2008). 
86. Dybzinski, R., Farrior, C., Wolf, A., Reich, P. B. \& Pacala, S. W. Evolutionarily stable strategy carbon allocation to foliage, wood, and fine roots in trees competing for light and nitrogen: an analytically tractable, individual-based model and quantitative comparisons to data. Am. Nat. 177, 153-166 (2011)

87. Farrior, C., Bohlman, S., Hubbell, S. \& Pacala, S. W. Dominance of the suppressed: power-law size structure in tropical forests. Science 351, 155-157 (2016).

88. Favier, C., Chave, J., Fabing, A., Schwartz, D. \& Dubois, M. A. Modelling forest-savanna mosaic dynamics in man-influenced environments: effects of fire, climate and soil heterogeneity. Ecol. Model. 171, 85-102 (2004).

89. Meron, E. Pattern-formation approach to modelling spatially extended ecosystems. Ecol. Model. 234, 70-82 (2012).

90. Rietkerk, M., Dekker, S. C., de Ruiter, P. C. \& van de Koppel, J. Self-organized patchiness and catastrophic shifts in ecosystems. Science 305, 1926-1929 (2004).

91. Meron, E. Pattern formation - a missing link in the study of ecosystem response to environmental changes. Math Biosci. 271, 1-18 (2016).

92. Gilad, E., von Hardenberg, J., Provenzale, A., Shachak, M. \& Meron, E. A mathematical model of plants as ecosystem engineers. J. Theor. Biol. 244, 680-691 (2007).

93. Glenn, E., Huete, A., Nagler, P. G. \& Nelson, S. Relationship between remotely-sensed vegetation indices, canopy attributes and plant physiological processes: what vegetation indices can and cannot tell us about the landscape. Sensors 8, 2136-2160 (2008).

94. Jaynes, E. T. Probability Theory: the Logic of Science (Cambridge Univ. Press, 2003).

95. Bertram, J. \& Dewar, R. C. Statistical patterns in tropical tree cover explained by the different water demand of individual trees and grasses. Ecology 94, 2138-2144 (2013).

96. Niinemets, U., Keenan, T. F. \& Hallik, L. A worldwide analysis of within-canopy variations in leaf structural, chemical and physiological traits across plant functional types. New Phytol. 205, 973-993 (2015).

97. Scheepens, J. F., Frei, E. S. \& Stöcklin, J. Genotypic and environmental variation in specific leaf area in a widespread Alpine plant after transplantation to different altitudes. Oecologia 164, 141-150 (2010)

98. Caldararu, S., Purves, D. W. \& Palmer, P. I. Phenology as a strategy for carbon optimality: a global model. Biogeosciences 11, 763-778 (2014).

99. Farrior, C. E. Theory predicts plants grow roots to compete with only their closest neighbours. P. Roy. Soc. B-Biol. Sci. 286, 20191129 (2019).

100. Chevin, L.-M., Lande, R. \& Mace, G. M. Adaptation, plasticity, and extinction in a changing environment: towards a predictive theory. PLoS Biol. 8, e1000357 (2010).

101. Kichenin, E., Wardle, D. A., Peltzer, D. A., Morse, C. W. \& Freschet, G. T. Contrasting effects of plant inter- and intraspecific variation on community-level trait measures along an environmental gradient. Funct. Ecol. 27, 1254-1261 (2013).

102. Shipley, B., Vile, D. \& Garnier, É. From plant traits to plant communities: a statistical mechanistic approach to biodiversity. Science 314, 812-814 (2006).

103. Getzin, S., Wiegand, K. \& Schöning, I. Assessing biodiversity in forests using very high-resolution images and unmanned aerial vehicles. Methods Ecol. Evol. 3, 397-404 (2012).

\section{Acknowledgements}

We thank the participants at the workshop titled 'Next-generation vegetation modelling', held at IIASA in March 2017: the idea for this Perspective arose from the insights and excitement engendered by the community discussion at that meeting. We also thank IIASA, both for their financial support of the workshop and for continued support thereafter. We particularly thank IIASA's former Director and CEO, P. Kabat, for his unfailing support for the next-generation vegetation modelling initiative. O.F. acknowledges funding provided by the Knut and Alice Wallenberg foundation. S.P.H. acknowledges the support from the European Research Council (ERC)-funded project titled 'Global Change 2.0: Unlocking the past for a clearer future' (GC2.0; grant no. 694481). This research is a contribution to the AXA Chair Programme in Biosphere and Climate Impacts and the Imperial College initiative on Grand Challenges in Ecosystems and the Environment (ICP). I.C.P. is supported by the ERC under the European Union's Horizon 2020 research and innovation programme (REALM; grant no: 787203). We also thank the Labex OTMed (grant no. ANR-11-LABX-0061) funded by the French Government Investissements d'Avenir program of the French National Research Agency (ANR) through the $\mathrm{A}^{\star}$ MIDEX project (grant no. ANR-11-IDEX-0001-02). S.Z. was supported by the European Research Council (ERC) under the European Union's Horizon 2020 research and innovation programme (QUINCY; grant no. 647204). J. Bertram supplied Fig. 5. S.J.S. is supported by the Luxembourg National Research Fund (FNR) ATTRACT programme (A16/SR/11254288). M.L. was supported by the TULIP Laboratory of Excellence (ANR-10-LABX-41). P.C. and J.P. were supported by the ERC under the European Union's Horizon 2020 research and innovation programme (IMBALANCE-P; grant no. ERC-SyG-2013-610028). P.C. acknowledges support from the CLAND institute of convergence of ANR in France (16-CONV-0003). I.J.W. was supported by the Australian Research Council (DP170103410). B.D.S. was funded by the Swiss National Science Foundation (grant no. PCEFP2_181115). S.M. is supported by the Swedish Research Councils VR (2016-04146) and Formas (2016-00998).

\section{Author contributions}

O.F., S.P.H., A.B., U.D., S.P., H.W., W.C., E.R. and I.C.P. contributed to the drafting of the paper; O.F. led the writing process; and R.D., C.E.F., D.F., M.L., H.W., I.C.P., K.T.R., Å.B., E.M. and O.F. contributed display items or specific sections. O.F., S.P.H., R.D., C.E.F. Å.B., U.D., S.P., D.F., W.C., M.L., H.W., A.M., K.T.R., E.M., S.J.S., E.R., B.D.S., S.Z., S.M., M.v.O., I.J.W., P.C., P.M.v.B., J.P., F.H., C.T., N.A.S., G.M. and I.C.P. contributed to the final version of the paper.

\section{Competing interests}

The authors declare that they have no competing interests.

\section{Additional information}

Supplementary information is available for this paper at https://doi.org/10.1038/ s41477-020-0655-x. 